\title{
Public awareness, beliefs and attitude towards depressive disorders in Saudi Arabia
}

\author{
Ahmed H. ALJadani, MD, Salman N. Alshammari, Medical student, Khalid A. Alshammari, Medical student, \\ Abdulaziz A. Althagafi, Medical student, Meshal M. AlHarbi, Medical student.
}

\begin{abstract}

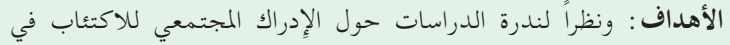

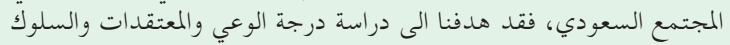
وخيارات العلاج المتاحة فيما يتعلق بالاكتئياب .

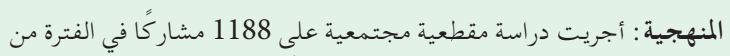

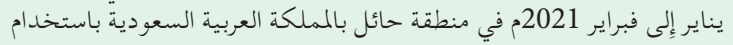

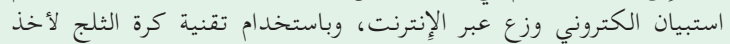

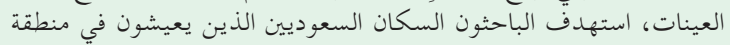

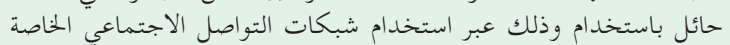

للوصول لهم.

النتائج : بشكل عام ، كان لدى \% 65.6 من المشار كين وعي جيد في كيما يتعلق

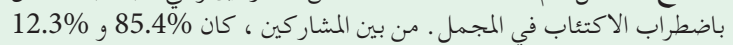




هو نتيجة للإصابة بالعين أو السحر، والئ واعتقد

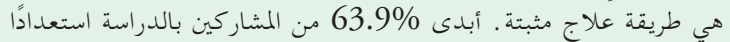

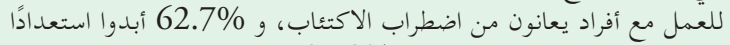


لديهم شخصيات ضعيفة.

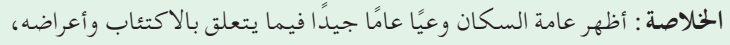



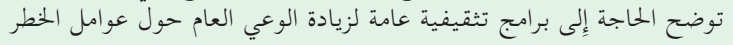

$$
\text { والخيارات العلاجية للاكتئاب. }
$$
\end{abstract}

Objectives: To investigate the degree of public awareness, beliefs, and attitudes regarding major depression and available treatment options in the Saudi population.

Methods: A community-based cross-sectional study of 1,188 participants was carried out from March to April 2021 in Ha'il, Saudi Arabia using an online self-administered questionnaire. Using a snowball sampling technique, the authors targeted the Saudi population living in Ha'il region.

Results: Overall, $65.6 \%$ of the participants had good awareness regarding depression disorder in total. Of the participants, $72.9 \%$ had good awareness regarding general awareness, $85.4 \%$ regarding depression symptoms, $12.3 \%$ regarding risk factors, and $15.7 \%$ regarding treatments. Of the participants, $67.3 \%$ believed that depression was caused by lack of faith and $45.5 \%$ believed that depression was caused by "the evil eye" or black magic. Of the participants, $56 \%$ believed in faith healers as a legitimate treatment approach. Of the participants, $63.9 \%$ were willing to work with individuals with depression, $62.7 \%$ were willing to establish friendships with them, and $27.9 \%$ believed that individuals with depression had weak personalities.

Conclusion: The general population exhibited good general awareness regarding depression and its symptoms, but knowledge of risk factors and treatments was poor. Our findings underscore the need for public educational programs to increase public awareness about the risk factors and treatment options for depression.

Keywords: depression, awareness, attitude, risk factors, Saudi

Saudi Med J 2021; Vol. 42 (10): 1117-1124 doi: 10.15537/smj.2021.42.10.20210425

From the Department of Internal Medicine (ALJadani), and from the College of Medicine (ALJadani, Alshammari S, Alshammari K, Althagafi, AlHarbi), University of Hail, Hail, Kingdom of Saudi Arabia.

Received 31st May 2021. Accepted 25th August 2021.

Address correspondence and reprint request to: Dr. Ahmed H. ALJadani, Internal Medicine Department, College of Medicine, University of Hail, Hail, Kingdom of Saudi Arabia. E-mail: Dra.aljadani@gmail.com ORCID ID: https://orcid.org/0000-0003-3614-9782

Disclosure. Authors have no conflict of interests, and the work was not supported or funded by any drug company. 
$\mathrm{D}$ epression is a prevalent illness that affects more than 264 million people worldwide. ${ }^{1}$ According to the diagnostic and statistical manual 5th edition, major depressive disorder is characterized by low mood, markedly diminished pleasure, feelings of low self-worth or guilt, insomnia or hypersomnia, psychomotor agitation or retardation, loss of energy or fatigue, significant weight loss or altered appetite, recurrent thoughts of death or suicide, and poor concentration. ${ }^{2}$ Disability-adjusted life years (DALYs) is an assessment employed to measure the burden of diseases by calculating the years of productive life lost due to disability or premature mortality. Mental and addictive disorders cause a considerable burden of disease. Reports have estimated that approximately 162 million DALYs were lost globally due to these disorders in 2016. ${ }^{3}$ Moreover, depression has a huge contribution towards global disability; it is listed by the World Health Organization (WHO) as the single largest factor. ${ }^{4}$ In Saudi Arabia, the lifetime prevalence of major depressive disorders (MDD) 6.0\%, and it is the third most common mental disorder. ${ }^{5}$

Although the etiology of depression has not been fully elucidated, various risk factors, including heritability, chronic diseases, unhealthy lifestyle, low socioeconomic status, a small social network, and widowhood, are linked to depressive disorders development. ${ }^{6}$ Psychosocial interventions, psychotropic medications, including antidepressants, and noninvasive brain stimulation modalities, such as transcranial magnetic stimulation (TMS) and electroconvulsive therapy (ECT), are effective treatment forms for depressive disorders. ${ }^{7}$ The lack of appropriate and timely treatment may have devastating consequences on patients' quality of life. Untreated depression is associated with a higher incidence of comorbidities, poor prognosis, delayed improvement among those with concomitant medical conditions, increased suicidal risk, and increased health care costs. ${ }^{8}$ Despite the existence of effective treatments, the majority of individuals with mental disorders remain untreated. ${ }^{9}$ In KSA, the probability of receiving treatment for MDD in the previous 12 months was only $10.6 \%$ underscoring the need to improve therapeutic accessibility and deployment. ${ }^{10}$

Knowledge and beliefs are associated with public attitudes toward mental illness and individuals with psychiatric disorders. ${ }^{11}$ General population beliefs and attitudes toward psychiatric disorders within the Arab community generally arise from a deep belief system that is supplemented by the present and past experiences of the community. The general population could perceive the treatment of psychiatric patients as ineffective, money and time consuming, and even risky. ${ }^{12}$
Public awareness data can be used to identify factors associated with the probability of seeking mental health care within targeted community groups. These data can be harnessed by healthcare policy makers to determine appropriate interventions. Hence, it is important to assess any gaps in the general population's awareness, beliefs, and attitudes toward various mental illnesses, their risk factors, and treatment options.

A study conducted in the Al-Jouf region, Northern KSA, found that $73.6 \%(n=425)$ participants had poor awareness regarding depression. In addition, the stigma was the most reported barrier that prevents patients from seeking mental health care. ${ }^{13}$ Another small audit study conducted in Riyadh, regarding the attitude of the Saudi community toward depression disorder revealed that $57.66 \%$ of participants $(n=137)$ attribute depression to supernatural powers, and $45.98 \%$ believe that antidepressant medication can cause addiction. ${ }^{14}$

Despite the high prevalence of depression, there is a paucity of studies on public perception regarding depression in KSA. This study aimed to investigate the degree of public awareness, beliefs, and attitudes regarding major depression and available treatment options in Ha'il region.

Methods. A community-based cross-sectional study was carried out from March to April 2021 among the Ha'il community in Saudi Arabia using an electronic questionnaire, which was distributed online by the researchers. Ethical approval was obtained from the Ha'il University Research Ethics Committee (approval number: 42/5/36836). The study was performed in accordance with the principles of the Declaration of Helsinki for studies involving human participants.

Participants who were younger than 18 years old, did not live in Ha'il, Saudi Arabia, were non-Arabic speakers, or worked as health care workers were excluded from this study. Using a snowball sampling technique, the authors targeted Saudi population living in Ha'il region, using their social media networks (WhatsApp and Telegram users), and encouraged their contacts to forward it to their social networks.

To determine the sample size for this study, we used the single population proportion formula. The analysis indicated that the minimum sample size required for this study was 381, with a confidence level of $95 \%$ and a margin of error of $5 \%$. In total, 1,521 participants were initially recruited. After the exclusion criteria were applied, the total number of enrolled participants was 1,188 .

The questionnaire consisted of 33 questions and comprised the following 3 parts: i) information on participants' sociodemographic data, including age, 
gender, marital status, nationality, level of education, occupation, monthly income, place of residence, and whether the participant was a medical worker; ii) assessed participants' awareness on the symptoms of major depression, risk factors contributing to the occurrence of depression, and different approaches employed in the management of this disorde; iii) questions regarding depression symptoms were adopted from the patient health questionnaire (PHQ)-9, a valid scale with Arabic translation used to screen for depressive symptoms and their severity. ${ }^{15}$ Participants were requested to describe their individual attitudes toward patients with depression in the third part of the questionnaire. Each question comprised 2 responses: 'agree' or 'disagree'. The Questionnaire was reviewed and approved by 2 psychiatric consultants and tested for both readability and comprehension by 25 participants who were not included in the study.

Informed consent was obtained from participants via the electronic questionnaire. Agreement to complete the anonymized online questionnaire was accepted as willingness to participate in the study. Confidentiality of participants was maintained, as no addresses or names were required.

The literature search method to find prior related research was conducted throughout January 2021. Medline and Scopus literature searches were conducted using the following keywords (awareness or knowledge), depression, and Saudi. These keywords were appropriate terms pertaining to the topic and area with no time frame limit.

Statistical analysis. Data was extracted, revised, coded, and entered using the Statistical Package for Social Sciences for Windows, version 22 (IBM Corp., Armonk, NY, USA). Statistical analysis was performed using 2-tailed tests. A $p$-value $<0.05$ was considered significant. For awareness domains, each correct answer within each domain was provided one point. The total sum of discrete scores for each item was calculated. Patients with scores less than $60 \%$ of the total score for each domain and overall score were considered to have poor awareness, whereas good awareness was defined as scores of $60 \%$ or higher of the total score. Descriptive analysis was performed for all variables based on frequency and percent distribution. Cross tabulation was used to assess the distribution of awareness according to participants' personal data. Relationships between variables were assessed using the Pearson's Chi-square test.

Results. A total of 1,188 respondents were enrolled in this study. The mean age of participant was $27.6 \pm 10.3$ years. Of participants, $624(52.5 \%)$ were females and $723(60.9 \%)$ were single. The sociodemographic data of the study participants is presented in Table 1.

Overall, $65.6 \%$ of participants had good awareness regarding depression disorder in total. Of participants, $72.9 \%$ had good awareness regarding general awareness, $85.4 \%$ regarding depression symptoms, $12.3 \%$ of risk factors, and $15.7 \%$ regarding treatments (Figure 1).

Of respondents, $96.9 \%$ concurred that depression is a treatable illness, $94.3 \%$ reported that depressive disorder may affect individuals in different age groups, and $89.4 \%$ believed that depression could be regulated by willpower. Regarding awareness of depression symptoms, the most commonly reported symptoms were severe sadness $(92.8 \%)$, followed by sleep disturbances (insomnia or hypersomnia; $90.2 \%$, Table 2).

Concerning risk factors contributing to the development of depression, $67.5 \%$ of the participants reported unemployment, followed by lack of faith $(67.3 \%)$, poverty $(57.8 \%)$, drug or alcohol abuse (48.7\%), and evil eye or black magic (45.5\%). Regarding treatments for depression, the most commonly identified

Table 1 - Sociodemographic data of study participants, Kingdom of Saudi Arabia.

\begin{tabular}{|c|c|}
\hline Sociodemographic data & $\mathrm{n}(\%)$ \\
\hline \multicolumn{2}{|l|}{ Age in years } \\
\hline $\begin{array}{l}18-24 \\
25-34 \\
35-44 \\
45-54 \\
55+\end{array}$ & $\begin{array}{c}577(48.6) \\
266(22.4) \\
167(14.1) \\
126(10.6) \\
52(4.4)\end{array}$ \\
\hline \multicolumn{2}{|l|}{ Gender } \\
\hline $\begin{array}{l}\text { Male } \\
\text { Female }\end{array}$ & $\begin{array}{l}564(47.5) \\
624(52.5)\end{array}$ \\
\hline \multicolumn{2}{|l|}{ Nationality } \\
\hline $\begin{array}{l}\text { Saudi } \\
\text { Non-Saudi }\end{array}$ & $\begin{array}{c}1159(97.6) \\
29(2.4)\end{array}$ \\
\hline \multicolumn{2}{|l|}{ Marital status } \\
\hline $\begin{array}{l}\text { Single } \\
\text { Married } \\
\text { Divorced/widow }\end{array}$ & $\begin{array}{c}723(60.9) \\
433(36.4) \\
32(2.7)\end{array}$ \\
\hline \multicolumn{2}{|l|}{ Educational level } \\
\hline $\begin{array}{l}\text { Below secondary } \\
\text { Secondary } \\
\text { University/above }\end{array}$ & $\begin{array}{c}37(3.1) \\
304(25.6) \\
847(71.3)\end{array}$ \\
\hline \multicolumn{2}{|l|}{ Work } \\
\hline $\begin{array}{l}\text { Not working } \\
\text { Student } \\
\text { Working }\end{array}$ & $\begin{array}{l}267(22.5) \\
541(45.5) \\
380(32.0)\end{array}$ \\
\hline \multicolumn{2}{|c|}{ Monthly income (Saudi Riyals) } \\
\hline $\begin{array}{l}<5000 \\
5000-10000 \\
10000-15000 \\
>15000\end{array}$ & $\begin{array}{c}761(64.1) \\
190(16.0) \\
145(12.2) \\
92(7.7)\end{array}$ \\
\hline
\end{tabular}




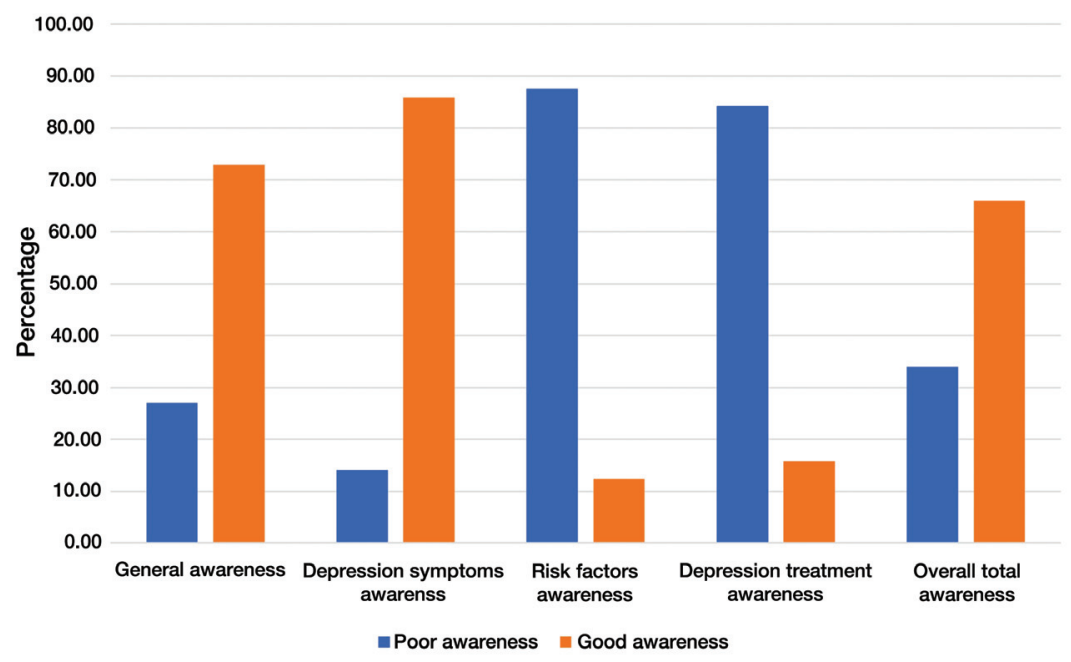

Figure 1 - Awareness level regarding different aspects of depression among general population in Saudi Arabia.

Table 2 - Public awareness regarding depression and depression symptoms in Saudi Arabia.

\begin{tabular}{lcc}
\hline Domain & Disagree & Agree \\
& & $\mathbf{n}(\%)$ \\
\hline General awareness & & \\
$\quad$ Depression is a psychiatric disorder & $133(11.2)$ & $1055(88.8)$ \\
Depression is a treatable illness & $37(3.1)$ & $1151(96.9)$ \\
Depression can be controlled by willpower & $126(10.6)$ & $1062(89.4)$ \\
Depression may affect anyone at any age & $68(5.7)$ & $1120(94.3)$ \\
Causes of depression are well known scientifically & $500(42.1)$ & $688(57.9)$ \\
Depression runs in families & $852(71.7)$ & $336(28.3)$ \\
Symptoms of depression & & \\
Loss of interest in things or usual activities & $143(12.0)$ & $1045(88.0)$ \\
Feeling of worthlessness or guilt & $175(14.7)$ & $1013(85.3)$ \\
Severe sadness & $85(7.2)$ & $1103(92.8)$ \\
Tiredness and lack of energy & $162(13.6)$ & $1026(86.4)$ \\
Reduced appetite or increased cravings for food & $241(20.3)$ & $947(79.7)$ \\
Sleep disturbances (insomnia or sleeping too much) & $116(9.8)$ & $1072(90.2)$ \\
Slow thinking, speaking, or body movements or anxiety, agitation, and restlessness. & $295(24.8)$ & $893(75.2)$ \\
Trouble concentrating in things like reading newspaper or watching television. & $391(32.9)$ & $797(67.1)$ \\
Thoughts of death (suicidal thoughts, suicide attempts or suicide) & $251(21.1)$ & $937(78.9)$ \\
\hline
\end{tabular}

approaches were support from family and friends (88.4\%), cognitive behavioral therapy $(65.0 \%)$, faith healers $(56.0 \%)$, exercise $(55.1 \%)$, and antidepressants (46.7\%) (Table 3).

Attitudes toward depression and individuals with depression among the general population are presented in Table 4. Of participants, $63.9 \%$ were willing to work with individuals with depression, $62.7 \%$ were willing to form friendships with them, and $27.9 \%$ responded that patients with depression had weak personalities. The most reported sources of help for addressing depressive symptoms were self-help (39.6\%), followed by family and friends (30.6\%), and psychiatrists (24.5\%).

The distribution of participants' awareness regarding depression according to demographic data is presented in Table 5. Good awareness was detected in $68.1 \%$ of the young age group $(<25$ years old $)$ and in $53.8 \%$ of the old age group ( $>55$ years old), with 
Table 3 - Public awareness regarding depression risk factors and treatments in Saudi Arabia.

\begin{tabular}{lc}
\hline Awareness items & $\mathbf{n}(\%)$ \\
\hline Risk factors related to the development of depression & \\
Unemployment & $802(67.5)$ \\
Lack of faith & $800(67.3)$ \\
Poverty & $687(57.8)$ \\
Drugs or alcohol misuse & $579(48.7)$ \\
Envy or magic & $540(45.5)$ \\
Severe diseases & $446(37.5)$ \\
Heavy work & $232(19.5)$ \\
Marriage & $80(6.7)$ \\
Treatments for depression & \\
Support from family and friends & $1050(88.4)$ \\
Cognitive behavioral therapy & $772(65.0)$ \\
Faith healers & $665(56.0)$ \\
Exercise & $654(55.1)$ \\
Antidepressants & $555(46.7)$ \\
Vitamins and minerals & $427(35.9)$ \\
Electroconvulsive therapy & $44(3.7)$ \\
Transcranial magnetic stimulation & $32(2.7)$ \\
\hline
\end{tabular}

Table 4 - Attitude towards depression and depressed persons among general population in Saudi Arabia.

\begin{tabular}{lc}
\hline Attitude & $\mathbf{n}(\%)$ \\
\hline Attitude items & \\
Depression patients have weak personality & $332(27.9)$ \\
I am willing to work with them & $759(63.9)$ \\
I am willing to make friends with them & $745(62.7)$ \\
I am willing to marry one with depression & $306(25.8)$ \\
They are mentally retarded & $47(4.0)$ \\
Person for seeking help in case of depressive symptoms & \\
development & \\
Self-help & $470(39.6)$ \\
Family/friends & $363(30.6)$ \\
Psychiatrist & $291(24.5)$ \\
Psychologist & $58(4.9)$ \\
General practitioner & $6(0.5)$ \\
\hline
\end{tabular}

a significant difference observed between age groups ( $p=0.049$ ). Further, $68.9 \%$ of female participants had good awareness regarding depression, whereas only $62.8 \%$ of male participants exhibited good awareness regarding depression, with a significant difference noted between genders $(p=0.027)$. No significant difference in awareness was observed between participants that were university graduates $(65.7 \%)$ and those with lower educational levels $(54.1 \% ; p=0.061)$.
Table 5 - Distribution of participants' awareness regarding depression by their personal data.

\begin{tabular}{|c|c|c|c|}
\hline \multirow[t]{2}{*}{ Personal data } & \multicolumn{2}{|c|}{ Overall awareness level } & \multirow[t]{2}{*}{$P$-value } \\
\hline & Poor & Good & \\
\hline \multicolumn{4}{|l|}{ Age in years } \\
\hline $\begin{array}{l}18-24 \\
25-34 \\
35-44 \\
45-54 \\
>55\end{array}$ & $\begin{array}{c}184(31.9) \\
89(33.7) \\
54(32.3) \\
52(41.3) \\
24(46.2)\end{array}$ & $\begin{array}{l}393(68.1) \\
175(66.3) \\
113(67.7) \\
74(58.7) \\
28(53.8)\end{array}$ & 0.049 \\
\hline \multicolumn{4}{|l|}{ Gender } \\
\hline $\begin{array}{l}\text { Male } \\
\text { Female }\end{array}$ & $\begin{array}{l}209(37.2) \\
194(31.1)\end{array}$ & $\begin{array}{l}353(62.8) \\
430(68.9)\end{array}$ & 0.027 \\
\hline \multicolumn{4}{|l|}{ Marital status } \\
\hline $\begin{array}{l}\text { Single } \\
\text { Married } \\
\text { Divorced/widow }\end{array}$ & $\begin{array}{c}231(32.0) \\
158(36.5) \\
14(43.8)\end{array}$ & $\begin{array}{c}490(68.0) \\
275(63.5) \\
18(56.3)\end{array}$ & 0.150 \\
\hline \multicolumn{4}{|l|}{ Educational level } \\
\hline $\begin{array}{l}\text { Below secondary } \\
\text { Secondary } \\
\text { University/above }\end{array}$ & $\begin{array}{c}17(45.9) \\
96(31.6) \\
290(34.3)\end{array}$ & $\begin{array}{c}20(54.1) \\
208(68.4) \\
555(65.7)\end{array}$ & 0.061 \\
\hline \multicolumn{4}{|l|}{ Work } \\
\hline $\begin{array}{l}\text { Not working } \\
\text { Student } \\
\text { Working }\end{array}$ & $\begin{array}{l}102(38.2) \\
171(31.6) \\
130(34.4)\end{array}$ & $\begin{array}{l}165(61.8) \\
370(68.4) \\
248(65.6)\end{array}$ & 0.173 \\
\hline \multicolumn{4}{|c|}{ Monthly income (Saudi Riyals) } \\
\hline $\begin{array}{l}<5000 \\
5000-10000 \\
10000-15000 \\
>15000\end{array}$ & $\begin{array}{c}253(33.2) \\
67(35.6) \\
57(39.3) \\
26(28.3)\end{array}$ & $\begin{array}{l}508(66.8) \\
121(64.4) \\
88(60.7) \\
66(71.7)\end{array}$ & 0.309 \\
\hline
\end{tabular}

Discussion. This study aimed to assess public awareness, beliefs, and attitudes regarding depressive disorder in Ha'il. Limited understanding and erroneous beliefs on mental illness contribute to deep-rooted negative attitudes towards those with mental illness. ${ }^{16,17}$

The current study demonstrated that $65.6 \%$ of participants had good general knowledge regarding depression in total, with the greatest knowledge observed in the area of depression symptoms. In contrast, awareness regarding the risk factors $(12.5 \%)$ and treatment approaches (15.7\%) for depression was low. These findings may be partly underpinned by the relative ease of understanding depression symptoms in contrast to risk factors and treatment modalities that necessitate deeper understanding and changes in cultural beliefs regarding the causes of mental disorders and appropriate treatments. Nevertheless, we identified that general awareness of depression symptoms was higher 
in the Saudi population than in Nigeria, Bangladesh, Australia, and Canada. ${ }^{18-21}$ Moreover, the awareness level in our study was higher in the Saudi population living in Al-Jouf region. ${ }^{13}$ This could be explained by the different methodologies used in our study.

Awareness was significantly higher in young females and those with high educational levels in our study. These results are consistent with previous studies that have assessed the determinants of awareness and attitudes toward mental illnesses. ${ }^{12,22}$ The significant gender differences may be associated with the lower prevalence of depression in males and consequent lack of exposure to this disorder. A possible factor is also that males may find it more difficult to discuss emotional factors that may limit them opening up on any symptoms they may experience.

Almost half of the respondents in our study believed that "the evil eye" or black magic were causal factors for depression, in accordance with various reports from different Arab countries. ${ }^{13,23,24}$ These results also agree with the findings from a study of Arab-American muslims that reported that $85.3 \%$ of participants believed that depression was a mental disorder, whereas $34.7 \%$ of participants reported that "the evil eye" or "black magic" could cause depression. ${ }^{25}$ Further, a large proportion of Arabs in Australia believe that psychiatric disorders are the result of $\sin$ or wrongdoing. ${ }^{26}$ In contrast, studies in Western societies have indicated that the public generally attributes depression to biological and psychosocial factors. ${ }^{20,21}$ This illustrates the effect of religion and cultural background on beliefs regarding mental illnesses. Indeed, in non-Western cultures, the causal underpinnings of psychiatric disorders are commonly attributed to the power of supernatural phenomena. $^{27}$

Majority of the respondents (89\%) in this study reported that depression could be controlled by willpower and $67.3 \%$ participants believed that lack of faith was a cause for depression. In another study in KSA, $97.8 \%$ participants believed that visiting a faith healer was a legitimate treatment option for patients with bipolar disorder. ${ }^{24} \mathrm{~A}$ crucial implication of this is that the community members may attribute this mental illness to weakness in personality or religious beliefs. Consequently, this may increase stigma and negatively impact attitudes on seeking mental healthcare. This may at least partly explain the observation that majority of participants $(70.6 \%)$ stated that they would not seek help from mental health professionals for their depression. In contrast, $82.6 \%$ Canadian men reported that they would seek professional help if they developed depression. ${ }^{28}$
In this study, $88.4 \%$ participants reported that family and friends played a key role in the treatment of depression. However, only $30.6 \%$ participants stated that they would seek help from loved ones if they were depressed. Indeed, individuals may be more hesitant to discuss mental disorders than physical disorders with relatives and friends. ${ }^{19}$

An Australian national survey reported that $47.8 \%$ of participants regarded taking antidepressants, 50.4\% taking vitamins or minerals, $92 \%$ performing physical activity, and $44.4 \%$ undergoing psychotherapy, as being helpful for treating depression. ${ }^{20} \mathrm{~A}$ Canadian survey reported that $62.2 \%$ participants regarded taking antidepressants, $60.8 \%$ taking vitamins or minerals, $96.5 \%$ performing physical activity, and $58.5 \%$ undergoing psychotherapy, as being helpful for treating depression. ${ }^{21}$ Another study carried out in KSA reported that $27 \%$ participants regarded taking medications, $4.7 \%$ herbal treatments, $33.4 \%$ spiritual intervention, and $76 \%$ psychotherapy intervention, as being helpful for treating depression. ${ }^{13}$ In this study, we observed that $46.7 \%$ of participants considered taking antidepressants, $35.9 \%$ taking vitamins or minerals, $55.1 \%$ performing physical activity, and $65 \%$ undergoing psychotherapy, as being helpful for treating depression. Our finding shows that the Saudi population has lower awareness of depression treatment modalities (except for psychotherapy) than Australian and Canadian populations.

Only $3.7 \%$ of participants believed that ECT could be used to treat depression despite the safety of this approach as a treatment for depression, and it is considered as a gold standard treatment for patients with otherwise treatment-resistant depression. ${ }^{29}$ These results are similar to those of a study in KSA reporting that only $12.7 \%$ of the Saudi population believed that ECT could be used to treat bipolar disorder. ${ }^{24}$ In this regard, educational interventions have been demonstrated to improve awareness and attitudes toward ECT. ${ }^{29,30}$ Further, we observed that almost all participants $(97.3 \%)$ were unaware of TMS. The effect size for TMS is largely beneficial and is recommended for the treatment-resistant or treatment-intolerant patients with depression. ${ }^{31}$ The poor knowledge ofTMS observed in this study may be explained by unfamiliarity to this type of treatment provided the paucity of centers providing such therapy in KSA.

The current study indicated relatively good perception and positive attitudes toward individuals with depression. Of participants, $62.7 \%$ reported that they were willing to form friendships and work with 
individuals with depression, and majority of participants disagreed on the concept of depression being linked to mental retardation. Moreover, approximately a third of participants stated that they would seek help from mental health professionals if they developed depression. In developing countries, mental health services are underutilized due to stigma and beliefs on these conditions as being due to sorcery or spiritual penalty. ${ }^{32}$ Factors associated with better attitudes toward individuals with psychiatric disorders, mental health services, and improved help-seeking behavior include a weaker effect of traditional beliefs and deeper knowledge on mental disorders. ${ }^{17}$

Collectively, our findings underscore the need to improve education in the Saudi population regarding depression and increase awareness on the availability and benefits of health services. Our findings emphasize the need for public health initiatives to improve community understanding of depression, especially its causes, treatments, and approaches to care.

Study limitations. This was a cross-sectional study that relied on self-reports. We used the snowball sampling method, which can cause a biased study population. Majority of the study population were young, single, and with higher education. Additionally, respondents may have been more interested in mental health compared to the general population provided that they voluntarily opted to complete the survey. Moreover, the target population included adults living in Ha'il region; therefore, the generalizability of the current findings to the wider Saudi population may be limited. Further studies incorporating larger sample sizes, more variables, and coverage of all regions in Saudi Arabia are warranted to address these limitations.

In conclusion, this study assessed the degree of public perception and attitudes regarding depressive disorders and available treatment options in Ha'il. The general population exhibited positive responses regarding awareness of depression and symptoms; however, awareness of risk factors and treatments was poor. Based on our findings, public educational programs related to depression should focus on increasing public awareness on the risk factors and treatment options for depression. Mental health promotion and educational efforts are warranted to improve mental health literacy and clarify misconceptions regarding depression in the general public. Particularly, these efforts should target older males.

Further studies are required to identify the optimal public interventions to improve knowledge on depression risk factors and treatment.
Acknowledgment. The authors gratefully acknowledge all the individuals who participated in filling the survey of this study. We would like to thank Editage (www.editage.com) for English language editing.

\section{References}

1. World Health Organiztions. Depression. [Updated 2020; Accessed $2021 \mathrm{March}$ ]. Available from: https://www.who.int/ news-room/fact-sheets/detail/depression

2. Lam RW, McIntosh D, Wang J, Enns MW, Kolivakis T, Michalak EE, et al. Canadian network for mood and anxiety treatments (CANMAT) 2016 clinical guidelines for the management of adults with major depressive disorder: section 1. Disease burden and principles of care. Can J Psychiatry 2016; 61: 510-523.

3. Rehm J, Shield KD. Global burden of disease and the impact of mental and addictive disorders. Curr Psychiatry Rep 2019; 21: 10.

4. Liu Q, He H, Yang J, Feng X, Zhao F, Lyu J. Changes in the global burden of depression from 1990 to 2017: findings from the global burden of disease study. J Psychiatr Res 2020; 126 : 134-140.

5. Altwaijri YA, Al-Subaie AS, Al-Habeeb A, Bilal L, Al-Desouki M, Aradati M, et al. Lifetime prevalence and age-of-onset distributions of mental disorders in the Saudi national mental health survey. Int J Methods Psychiatr Res 2020; 29: e1836.

6. Schaakxs R, Comijs HC, van der Mast RC, Schoevers RA, Beekman ATF, Penninx BWJH. Risk factors for depression: differential across age? Am J Geriatr Psychiatry 2017; 25: 966-977.

7. Gautam S, Jain A, Gautam M, Vahia VN, Grover S. Clinical practice guidelines for the management of depression. Indian J Psychiatry 2017; 59: S34-S50.

8. Sartorius N. Depression and diabetes. Dialogues Clin Neurosci 2018; 20: 47-52.

9. Al-Subaie AS, Altwaijri YA, Al-Habeeb A, Bilal L, Almeharish A, Sampson NA, et al. Lifetime treatment of DSM-IV mental disorders in the Saudi national mental health survey. Int J Methods Psychiatr Res 2020; 29: e1837.

10. Al-Habeeb A, Altwaijri YA, Al-Subaie AS, Bilal L, Almeharish A, Sampson NA, et al. Twelve-month treatment of mental disorders in the Saudi national mental health survey. Int J Methods Psychiatr Res 2020; 29: e1832.

11. Abi Doumit C, Haddad C, Sacre H, Salameh P, Akel M, Obeid $S$, et al. Knowledge, attitude and behaviors towards patients with mental illness: results from a national Lebanese study. PLoS One 2019; 14: e0222172.

12. Abolfotouh MA, Almutairi AF, Almutairi Z, Salam M, Alhashem A, Adlan AA, et al. Attitudes toward mental illness, mentally ill persons, and help-seeking among the Saudi public and sociodemographic correlates. Psychol Res Behav Manag 2019; 12: 45-54.

13. Aletesh N, Alamrani S, Alshreef O, Alsharif Z, Alshehri M, Falah H, et al. Public awareness towards depression in Al-Jouf, Saudi Arabia. IJMDC 2021; 5: 876-884.

14. Alrhaili N, Almatham F, Haamed H, Ghaziuddin M. Attitudes to depression in Saudi Arabia: a preliminary study. Int J Cult Ment Health 2016; 9: 255-260.

15. AlHadi AN, AlAteeq DA, Al-Sharif E, Bawazeer HM, Alanazi $\mathrm{H}$, AlShomrani AT, et al. An arabic translation, reliability, and validation of patient health questionnaire in a Saudi sample. Ann Gen Psychiatry 2017; 16: 32. 
16. Mannarini S, Rossi A. Assessing mental illness stigma: a complex issue. Front Psychol 2019; 9: 2722.

17. Alsubaie S, Almathami M, Alkhalaf H, Aboulyazid A, Abuhegazy H. A survey on public attitudes toward mental illness and mental health services among four cities in Saudi Arabia. Neuropsychiatr Dis Treat 2020; 16: 2467-2477.

18. Akinsulore A, Esimai OA, Mapayi BM, Aloba OO. Public awareness and attitude towards depression: a community based study among an adult population in Ile-Ife South-Western Nigeria. Community Ment Health J 2018; 54: 866-874.

19. Uddin MN, Bhar S, Islam FMA. An assessment of awareness of mental health conditions and its association with sociodemographic characteristics: a cross-sectional study in a rural district in Bangladesh. BMC Health Serv Res 2019; 19: 562.

20. Jorm AF, Christensen H, Griffiths KM. The public's ability to recognize mental disorders and their beliefs about treatment: changes in Australia over 8 years. Aust N Z J Psychiatry 2006; 40: 36-41.

21. Wang J, Adair C, Fick G, Lai D, Evans B, Perry BW, et al. Depression literacy in Alberta: findings from a general population sample. Can J Psychiatry 2007; 52: 442-449.

22. Picco L, Abdin E, Chong SA, Pang S, Shafie S, Chua BY, et al. Attitudes toward seeking professional psychological help: factor structure and socio-demographic predictors. Front Psychol 2016; 7: 547.

23. Zolezzi M, Alamri M, Shaar S, Rainkie D. Stigma associated with mental illness and its treatment in the Arab culture: a systematic review. Int J Soc Psychiatry 2018; 64: 597-609.

24. Alosaimi FD, AlAteeq DA, Bin Hussain SI, Alhenaki RS, Bin Salamah AA, AlModihesh NA. Public awareness, beliefs, and attitudes toward bipolar disorder in Saudi Arabia. Neuropsychiatr Dis Treat 2019; 15: 2809-2818.
25. Shebak SS, Elkhatib AM, Albiatty H, Elsayed T, Sobh H, El Deen MBM, et al. Attitudes toward depression in ArabAmerican muslims: a pilot study. Prim Care Companion CNS Disord 2019; 21: 19m02499.

26. Slewa-Younan S, Guajardo MGU, Mohammad Y, Lim H, Martinez G, Saleh R, et al. An evaluation of a mental health literacy course for Arabic speaking religious and community leaders in Australia: effects on posttraumatic stress disorder related knowledge, attitudes and help-seeking. Int J Ment Health Syst 2020; 14: 69.

27. Hankir A, Khalil S, Wadood Q, Madarbukus D, Yunus HA, Bibi $S$, et al. The federation of student islamic societies programme to challenge mental health stigma in muslim communities in England: the FOSIS Birmingham study. Psychiatr Danub 2017; 29: 512-520.

28. Ogrodniczuk JS, Oliffe JL, Black N. Canadian men's perspectives of depression: awareness and intention to seek help. Am J Mens Health 2017; 11: 877-879.

29. Basso L, Bönke L, Aust S, Gärtner M, Heuser-Collier I, Otte $\mathrm{C}$, et al. Antidepressant and neurocognitive effects of serial ketamine administration versus ECT in depressed patients. $J$ Psychiatr Res 2020; 123: 1-8.

30. Hoffman GA, McLellan J, Hoogendoorn V, Beck AW. Electroconvulsive therapy: the impact of a brief educational intervention on public knowledge and attitudes. Int $Q$ Community Health Educ 2018; 38: 129-136.

31. Kar SK. Predictors of response to repetitive transcranial magnetic stimulation in depression: a review of recent updates. Clin Psychopharmacol Neurosci 2019; 17: 25-33.

32. Zhang Z, Sun K, Jatchavala C, Koh J, Chia Y, Bose J, et al. Overview of stigma against psychiatric illnesses and advancements of anti-stigma activities in six Asian societies. Int J Environ Res Public Health 2019; 17: 280. 